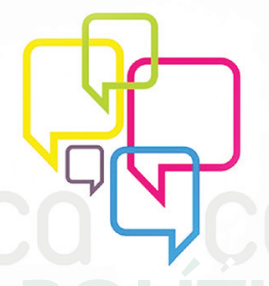

açãô Imidiática

N. 6 | Ano 2013

Universidade Federal do Paraná | Programa de Pós-Graduação em Comunicação

\title{
Comunicação pública e mídias sociais: possibilidades e limitações ${ }^{1}$
}

Public communication and social media: possibilities and limitations

Comunicación pública y medias sociales: posibilidades y limitaciones

Tiago MAINIERI ${ }^{2}$

Eva Márcia RIBEIRO3

\section{RESUMO}

O artigo discute o papel das mídias sociais no contexto da comunicação pública. O estudo norteia-se pelo entendimento de que a comunicação pública é aquela comunicação focada no cidadão e que prioriza as questões de interesse coletivo. Ao analisar o twitter do governador de Goiás, à luz dos preceitos de uma comunicação voltada ao interesse público, pretende-se refletir o papel das mídias sociais como um instrumento de interlocução à disposição dos cidadãos e a serviço de uma verdadeira comunicação pública.

Palavras-chave: Comunicação pública; Mídias sociais; Twitter; Cidadania.

\begin{abstract}
This article discuss the social media role in public communication context. The study priories the understanding of public communication as a communication focus on the citizenship and the public interest. Analyzing the Twitter, under the perspective of public interest, we propose to reflect the media social role as instrument of dialog available to citizens and serving as a truly public communication.
\end{abstract}

Keywords: Public communication; Internet; Social media; Twitter, Citizenship.

\section{RESUMEN}

El artículo discute el papel de las medias sociales en el contexto de la comunicación pública. Ese estudio propone el entendimiento de que la comunicación pública es aquella comunicación cuyo ciudadano es figura central asi como las cuestiones de interés público. A analizar el Twitter, refletar el role de las medias sociales como un instrumento de dialogo a disposición de los ciudadanos y a servicio de una verdadera comunicación pública.

Palabras clave: Comunicación pública; Internet; Media sociales; Twitter; Ciudadanía.

1 Trabalho apresentado à sexta edição da Revista Ação Midiática - Estudos em Comunicação, Sociedade e Cultura, publicação ligada ao Programa de Pós-Graduação em Comunicação, da Universidade Federal do Paraná.

2 Professor do Programa de Pós-Graduação em Comunicação (Mestrado) da Faculdade de Informação e Comunicação da Universidade Federal de Goiás (FIC/UFG). Bolsista de Pós-doutorado Júnior do CNPq na ECO/UFRJ. Doutor em Ciências da Comunicação pela Universidade de São Paulo (ECA/USP), mestre e bacharel pela UFSM. Líder do grupo de estudos e pesquisa da Comunicação em Contextos Organizacionais - CNPq/UFG e integrante do Laboratório de Leitura Crítica da Mídia da UFG. tiagomainieri@gmail.com

3 Mestre em Comunicação e bacharel em Relações Públicas pela Universidade Federal de Goiás. eva arantes@hotmail.com 


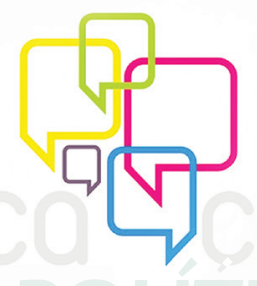

\section{ação}

Estudos em Comunicação, Sociedade e Cultura

N. 6 | Ano 2013

\section{Universidade Federal do Paraná | Programa de Pós-Graduação em Comunicação}

\section{A perspectiva das mídias sociais para uma comunicação dialógica}

Na perspectiva de Pierre Lévy e André Lemos, o virtual faz emergir uma nova esfera pública, que é denominada de esfera pública digital. Essa nova esfera pública tem como principal característica não se formar em um ambiente geográfico predefinido. Ela tem, na verdade, um alcance até mesmo mundial, sem restrições territoriais - ou ainda, como apontado por Habermas, não é mais estritamente face a face. Assim, essa esfera pública digital se funda em um espaço descentralizado, sendo sua comunicação caracterizada de muitos para muitos.

Seguindo esse pensamento, Rousiley Maia ressalta que "quando o debate público é ampliado, há maiores chances para se alcançar um compartilhamento do saber social para tratar de problemas complexos, que não podem ser resolvidos sem a cooperação coletiva" (MAIA, 2008, p. 191).

Diante desse cenário, o papel da internet nessa difusão é muito relevante. O fato é que a internet proporciona uma troca entre as pessoas, possibilitando que os atores sociais possam não só receber uma determinada opinião, mas, ainda, emitir a sua opinião sobre um determinado assunto, não precisando, como nos meios de comunicação de massa tradicionais, passar por intermediadores.

É importante salientar que concordamos com os autores que mostram a importância da internet na difusão de informações. Acreditamos que existe hoje uma esfera pública virtual, entretanto elas coexistem com as esferas públicas que acontecem em um ambiente geográfico, como apontado por Wilson Gomes e Rousiley Maia (2008). O que importa nessa reflexão, na verdade, é perceber que o papel das esferas públicas hoje, além de formar uma determinada opinião entre seus membros, também deve levar em conta a visibilidade que ela tende a buscar e como os assuntos tratados tendem a refletir em decisões políticas.

Wilson Gomes, em sua obra "Transformações da política na era da comunicação de massa", ressalta que "o advento do formato web da internet, no início dos anos 1990, trouxe consigo enormes expectativas no que diz respeito à renovação das possibilidades de participação democrática" (GOMES, 2004, p. 303).

De fato, a internet modifica intensamente a forma de relacionar entre as pessoas e também as características do processo democrático. Isso se dá porque, através da internet, há a possibilidade não apenas de transmissão de conteúdos e informações, mas também uma comunicação baseada no modelo todos por todos.

$\mathrm{Na}$ verdade, o advento da internet modifica a forma de participação política de uma sociedade, tornando mais visíveis os atos políticos e também modificando o processo de comunicação, tornando-o cada vez mais fundamentado no diálogo e em trocas simbólicas.

Tal processo de comunicação é entendido como o modelo todos-todos, de acordo com Lemos e Lévy (2010), ou seja, todos podem emitir e receber informações e trocar conteúdos ao 


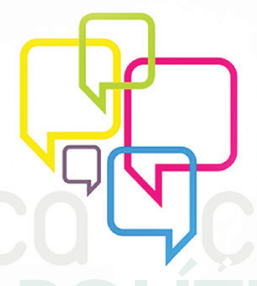

ação Imididiática

N. 6 | Ano 2013

Universidade Federal do Paraná | Programa de Pós-Graduação em Comunicação

mesmo tempo, por isso difere do modelo um-todos, que está ligado às mídias tradicionais que possuem o monopólio de transmissão de conteúdos para os seus receptores. Nesse modelo, o papel dos receptores era somente o de receber conteúdos e informações, sem ter a possibilidade de também ser emissor de suas próprias informações.

Percebe-se, de fato, que a internet possibilita uma maior visibilidade dos assuntos e dos atores políticos e, para além disso, possibilita que o cidadão não só receba informações, mas também seja um emissor de conteúdos. Essa é, na verdade, a maior contribuição da internet para a democracia, "é a visibilidade que ancora a discutibilidade na democracia" (GOMES, 2004, p. 303).

A questão é que, quanto mais visíveis forem os assuntos de interesse público, mais haverá espaço para discussões e participação do cidadão. Nesse sentido, devemos pensar o papel que as mídias sociais desempenham ou podem desempenhar para estimular a prática e o exercício da comunicação pública.

De fato, as redes sociais possibilitam maior participação, numa relação dialógica entre os sujeitos. Tal diálogo não acontece numa relação face a face. O que se tem, na verdade, é uma comunicação que também é mediada, nesse caso pelo computador. Porém, mesmo sendo mediada, não se caracteriza uma comunicação que anula a potencialidade crítica do sujeito receptor. Pelo contrário, ela possibilita uma participação do receptor também como emissor de conteúdos, e não apenas no seu papel fixo de recepção, como acontece por mediação realizada através de outros meios de comunicação de massa. Aqui, o indivíduo sempre ressignifica as mensagens recebidas e retransmite as mesmas, de acordo com seu nível de entendimento e percepção.

No caso das mídias sociais, o processo de retransmitir torna-se mais fácil. O fato é que essas mídias possibilitam uma comunicação mais aproximativa entre sujeito e receptor; uma relação que não designa mais tão somente o papel do emissor e do receptor, tendo o primeiro apenas como emissor de mensagens e o segundo apenas como receptor. E é nesse sentido que as mídias sociais podem estimular a prática da comunicação pública, conforme analisamos ao longo do texto, já que possibilitam uma participação mais interativa e participativa no processo de comunicação.

\section{Para uma comunicação voltada ao interesse coletivo}

O conceito de "comunicação pública" é polissêmico, por isso não existe uma única definição para o termo. Autores como Elizabeth Brandão e Maria José da Costa Oliveira dedicam-se na tentativa de explorar as diversas abordagens e enfoques acerca do conceito de comunicação política e governamental.

O fato é que entendemos que a comunicação governamental visa à prestação de 


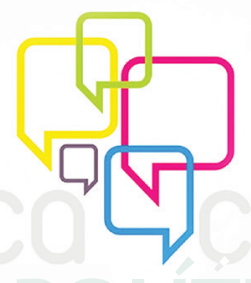

açãô Mididiática

N. 6 | Ano 2013

Universidade Federal do Paraná | Programa de Pós-Graduação em Comunicação

contas de um determinado governo para a sociedade. Já a comunicação política associa essa comunicação ao marketing político, utilizando para isso estratégias de comunicação persuasiva e de convencimento.

Para saber como se dá essa comunicação, é importante deixar claro o que é e o que não pode ser considerado comunicação pública. Por esse motivo, tornou-se relevante ressaltar aqui o conceito de comunicação política e governamental.

A fim de definirmos o conceito de comunicação pública, apoiamo-nos em diferentes autores, tais como Elizabeth Brandão, Heloiza Matos, Jorge Duarte e outros, cuja base teórica tem como fundamento o pensamento de Pierre Zémor (1995).

De acordo com Zémor, a função precípua da comunicação pública é a informação, porém ela deve ir além do mero processo informativo. Pierre Zémor ressalta cinco categorias para identificar a comunicação pública.

1. Responder à obrigação que têm as instituições públicas de levar informação a seus públicos;

2. Estabelecer a relação e o diálogo de forma a desempenhar o papel que cabe aos poderes públicos, bem como para permitir que o serviço público atenda às necessidades do cidadão de maneira mais precisa;

3. Apresentar e promover cada um dos serviços oferecidos pela administração pública;

4. Tornar conhecidas as instituições a elas mesmas, tanto por comunicação interna quanto externa;

5. Desenvolver campanhas de informação e ações de comunicação de interesse geral. (ZÉMOR, 1995, p. 5)

Zémor destaca o papel da informação, como base e primeiro passo para que se estabeleça um diálogo com o cidadão. Desse modo, a comunicação pública deve estar a serviço do cidadão, ampliando as perspectivas de interlocução. A partir da análise do twitter do governador Marconi Perillo, na sequência deste artigo, serão retomadas e aprofundadas as ideias de Zémor e de outros autores.

\section{Estudo do twitter do governador de Goiás, Marconi Perillo}

Fundamentados na concepção de comunicação pública, conduziu-se o estudo do twitter do governador de Goiás, Marconi Perillo. Para esse estudo, fruto de dissertação de mestrado, foram analisadas as respostas obtidas nos questionários aplicados com os seguidores, com a equipe de mídias sociais e com o próprio governador, a fim de perceber se o governador estabelece ou não uma comunicação pública com seus seguidores por meio de seu twitter.

A coleta de dados com os seguidores do twitter do governador Marconi Perillo começou no dia 16 de agosto de 2011 e teve como objetivo coletar 194 (cento e noventa e quatro) questionários, de acordo com cálculo amostral. A população para realização do cálculo amostral 


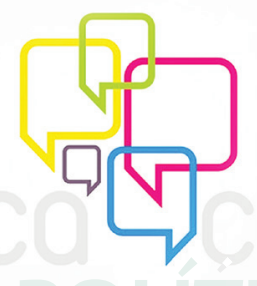

açås

Estudos em Comunicação, Sociedade e Cultura

N. 6 | Ano 2013

Universidade Federal do Paraná | Programa de Pós-Graduação em Comunicação

TweetRank, diz respeito à nota de influência do perfil pessoal do governador. O governador possui uma nota muito baixa de influência $(24,29)$, e, por essa razão, nem aparece na classificação nacional do ranking feito pelo site. Vale lembrar que a nota de influência está relacionada à interação entre o usuário do perfil e seus seguidores. É importante salientar também que apenas $24 \%$ dos seguidores que responderam esse questionário são seguidos pelo governador. $\mathrm{Na}$ verdade, esse dado confirma as informações de influência retiradas desse site, pois percebemos que $74 \%$ dos seguidores não são seguidos pelo governador.

Com esses dados, nota-se também que muitos seguidores não obtêm respostas para seus questionamentos, mesmo quando o governador e a assessora afirmam que todos os questionamentos são respondidos. Mais do que isso, a assessora ressaltou que o twitter possibilita uma relação online e permanente entre governador e cidadão. E afirmou que a intenção de ter o governador presente nessa mídia "é dar transparência, abrir canais de comunicação diretos de comunicação do governo com a sociedade".

Também perguntamos ao governador Marconi Perillo o objetivo de ter um perfil no twitter, e como já ressaltado pela assessora, o governador afirma que é pelo fato de essa mídia proporcionar um canal direto de comunicação e interação com o cidadão. Segundo suas palavras, "uma via de mão dupla com a sociedade". Desse modo, de acordo com essas respostas dadas pela assessora e o governador, entendemos que estar presente nas mídias sociais, abre canais de comunicação entre governador e cidadão. Conforme aponta Zémor (1995) em suas categorias, a comunicação pública deve transmitir informação a seus públicos e estabelecer relação e diálogo, de forma a desempenhar o papel que cabe aos poderes públicos.

Tanto o governador quanto a assessoria sempre ressaltam a capacidade que o twitter tem de gerar diálogos e interação entre governo e cidadão. Assim, a comunicação estabelecida via essa mídia, segundo ambos, vai além da mera emissão de informação e busca uma comunicação dialógica e interativa.

Outra característica apontada por Pierre Zémor, em relação à comunicação pública, diz respeito à necessidade de se desenvolver campanhas de informação e ações de comunicação de interesse geral. Nesse sentido, quando perguntado para a assessora como são selecionados os assuntos tratados via twitter, ela respondeu que não existe seleção: "desde que seja relevante para o público".

Na verdade, assuntos de interesse público são característicos da comunicação pública e, como aponta Graça França Monteiro, é necessário que as mensagens da comunicação pública "sejam fruto do debate público e propiciem o debate público" (MONTEIRO, 2007, p. 40). Pensando nessa questão, percebe-se que as mensagens postadas no twitter do governador, de acordo com suas respostas, em geral visam o interesse público.

Quando perguntado ao governador como são definidos os temas a serem tratados no 


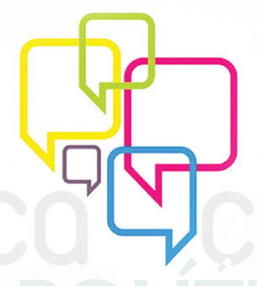

açås

Estudos em Comunicação, Sociedade e Cultura

N. 6 | Ano 2013

Universidade Federal do Paraná | Programa de Pós-Graduação em Comunicação

seu twitter, ele afirmou que, através do seu perfil pessoal, "converso com as pessoas, respondo algumas perguntas endereçadas a mim, falo de assuntos do governo e também da minha vida pessoal". É importante, mais uma vez, salientar que o governador tem mais dois perfis no twitter mantidos pela assessoria, cujo intuito é o de transmitir informações do governo.

Analisando o perfil pessoal do governador, observa-se que há a intenção de dialogar com algumas pessoas e também de responder algumas perguntas. Ou seja, o governador responde a quem deseja, fato esse também demonstrado quando se vê a maior quantidade de replies dados pelo seu perfil, por meio do site TweetStats.

A partir desses dados, entende-se que o governador usa essa mídia para transmitir informações e postar mensagens que nem sempre dizem respeito à coletividade. Por outro lado, vê-se que os perfis mantidos pela assessoria divulgam ações do governo, tais como eventos, agenda, etc., ou seja, tem como intuito divulgar ações do governo, informando o cidadão sobre o que o governador faz e como está seu governo. Segundo Pierre Zémor (1995), essa seria a função precípua da comunicação pública, entretanto ela deve ir além da mera informação.

É importante deixar claro que a comunicação informativa não estabelece uma comunicação de mão dupla, como enfatiza o governador em suas respostas sobre o objetivo de ter um perfil no twitter. Mas, entende-se que o twitter do governador Marconi Perillo abre canais de comunicação para o cidadão chegar ao governante, uma característica importante da comunicação pública, como também aponta Zémor (1995).

No questionário com os seguidores, perguntamos se eles já tinham enviado um questionamento ao governador. E tivemos como resposta que $70 \%$ nunca enviaram nenhuma pergunta ao governador; apenas $26 \%$ responderam que sim. Diante disso, vê-se que o cidadão nem sempre usa o twitter para se aproximar do governante. Ele tem o canal, mas nem sempre o usa para essa finalidade.

Para os seguidores que responderam que nunca postaram nada para o governador, perguntamos o motivo. E 44\% responderam que nunca tiveram interesse. Diante disso, o que vemos é que o canal de comunicação para aproximar o cidadão do governante foi criado. Porém, o seguidor, em sua maioria, nem sempre tem interesse para um diálogo.

Para a questão acerca da postagem para o governador, demos como alternativa a opção "Outros", que foi assinalada por $28 \%$ das respostas. Nessa categoria, as principais respostas dadas foram: que ainda não tem algo a dizer ao governador ou não tem interesse em enviar um questionamento. Algumas pessoas responderam que seguem o governador há pouco tempo, por esse motivo nunca mandaram um questionamento. Além disso, também foi ressaltado que nunca houve a postagem de um questionamento porque não se acreditava que o governador responderia pessoalmente ou mesmo que seria respondido. Nesse sentido, o seguidor percebe que nem sempre é o governador que responde aos questionamentos feitos ou que não terá 


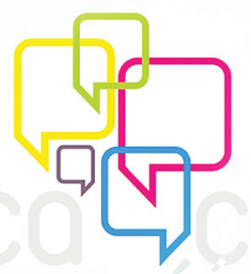

resposta. Isso mostra que nem sempre o twitter é percebido pelo seguidor como um locus de diálogo, sem a presença de intermediários, como foi enfatizado pelo governador.

Neste estudo, ressaltamos que o interesse público extrapola o interesse pessoal e está associado ao interesse de muitos, à busca de um bem-estar coletivo, como aponta Rousiley Maia (2011). Nessa perspectiva, cabe ressaltar que o seguidor que postou algo para o governador, $26 \%$ dos que responderam o questionário, tem interesse em discutir algum assunto relacionado ao governo e fazer cobranças via twitter. Pode-se entender com essa questão que os seguidores, quando postam algo para o governador (uma minoria das respostas obtidas), usam o twitter como ferramenta para se aproximar do governo, seja através de questionamentos com dúvidas e cobranças ou também para parabenizar o governador por alguma ação feita. Percebe-se, assim, que, quando julga necessário, o cidadão utiliza o twitter para ter acesso ao governador.

Outra pergunta feita apenas para quem enviou um questionamento para o governador, ou seja, $26 \%$ dos seguidores, estava relacionada ao recebimento de uma resposta por parte do governo: $62 \%$ assinalaram que não obtiveram respostas para seus questionamentos. Esse dado contradiz o que a assessora e o governador ressaltaram em suas respostas, a saber, que "faço o possível para responder todos os questionamentos. E pela impossibilidade de responder todos, o perfil @marconi_equipe responde aos usuários.” Na verdade, tal dado confirma as informações obtidas nos sites que analisam o perfil mantido pelo governador.

Entende-se que, para haver uma comunicação pública, é necessário haver uma comunicação dialógica. E, segundo esse dado, nem sempre há, pois muitas vezes, o cidadão fica sem respostas para seus questionamentos ou com respostas que não o satisfazem - e é interessante notar que o governador e a assessora sempre ressaltam que o intuito maior em estar presente nessa mídia é para estabelecer uma comunicação de mão dupla com o cidadão.

Vale ressaltar que, para $38 \%$ dos seguidores que obtiveram respostas ao seu questionamento, perguntamos sobre o tempo da resposta. A maioria respondeu que teve resposta no mesmo dia. Esse dado, aliás, vai ao encontro daquilo que a assessora aponta sobre a busca em responder os questionamentos feitos ao governador em um dia. O que se nota é que, quando são respondidos os questionamentos, as respostas são dadas num período de tempo muito dinâmico. Segundo diferentes autores abordados neste estudo, as mídias sociais possibilitam uma comunicação mais interativa e rápida.

Também percebemos que $89 \%$ dos seguidores ficaram satisfeitos com a resposta obtida. Esse dado comprova a profissionalização da equipe de mídias sociais do governador, como já mencionado na interpretação das respostas obtidas pela assessora e pelo governador.

Por fim, perguntamos a todos os seguidores o que eles acham das mensagens postadas no twitter do governador. E $41 \%$ responderam que as mensagens visam transmitir informações do governo, sendo que $26 \%$ responderam que as mensagens servem para aproximar o governador 

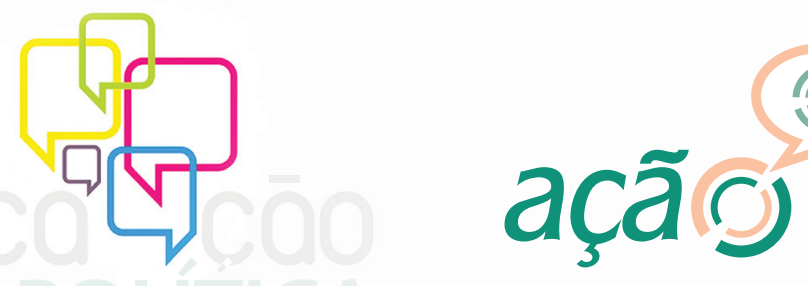

Estudos em Comunicação, Sociedade e Cultura

N. 6 | Ano 2013

\section{Universidade Federal do Paraná I Programa de Pós-Graduação em Comunicação}

do seguidor e $15 \%$ salientaram o fato de elas visarem ao estabelecimento de um diálogo com os seguidores.

Conforme as respostas obtidas nos questionários, percebe-se que, no que tange ao twitter do governador, os assuntos são tratados mais com o fim de estabelecer um canal de informação para o cidadão do que para discutir e debater algo de relevância e de interesse público. E quando existe um questionamento por parte do seguidor, há o intermédio da assessoria do governador para respondê-lo. Nem todos os seguidores são respondidos; quando são, alguns consideram a resposta como algo genérico ou é vista como algo automático.

A grande mudança proporcionada pelas mídias sociais é a de estabelecer uma comunicação sem intermediários, onde todos podem ser receptores e emissores de conteúdo. Nesse sentido, entendemos que no twitter do governador Marconi Perillo ainda existe a figura do intermediário, que é a sua assessoria, composta por quinze profissionais, como jornalistas, fotógrafos, designers, cinegrafistas e assistentes. Percebe-se que se trata de uma equipe bem qualificada para realizar essa intermediação entre governador e seguidor.

Um fato inegável é que existe o canal de comunicação. E vemos que o seguidor, a fim de se aproximar do governante, pode fazê-lo de forma direta. Ou seja, o cidadão, através do twitter tem um acesso mais fácil ao governador e às ações de seu governo. Mas 70\% dos seguidores nunca postaram nada para o governador, conforme dados já apontados. E desses, $44 \%$ responderam que nunca o fizeram por falta de interesse. Vê-se, assim, que também falta muito para os usuários das mídias sociais, neste caso o twitter, perceber que esta é uma mídia que possibilita a aproximação com o governante, e que, através dela, pode-se estabelecer um canal de comunicação pública.

Para alguns dos seguidores que não enviaram questionamento, há o descrédito, no sentido de não se acreditar que seja o governador que mantém o diálogo. Ou seja, existe uma falta de credibilidade por parte do twitter do governador.

Com os dados que colhemos, percebemos que, teoricamente, tanto o governador quanto a assessora de mídias sociais entendem o papel e importância das mídias sociais. Porém, o uso que fazem do twitter ainda é predominantemente para divulgar ações do governo. E o próprio seguidor reconhece isso. Basta observar o percentual de $41 \%$ que respondeu que o intuito das mensagens postadas no twitter do governador é transmitir informações do governo.

Como já apontado e bastante enfatizado nesse estudo, a comunicação pública deve ir além do processo informativo e buscar uma comunicação mais dialógica - fato percebido por $15 \%$ dos seguidores que responderam esse questionário. Essa informação se confirma também pela análise feita no site TweetRank. De acordo com esse site, podemos perceber que o número de seguidores do governador é crescente desde outubro. Porém, sua nota de influência, a que está relacionada com a interação com esses seguidores, é decrescente. Ou seja, o perfil mantido 


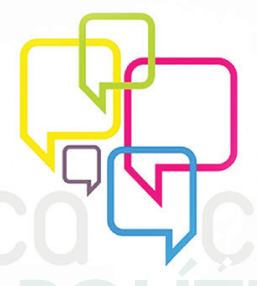

\section{açãos}

Estudos em Comunicação, Sociedade e Cultura

N. 6 | Ano 2013

Universidade Federal do Paraná | Programa de Pós-Graduação em Comunicação

Para tal, partimos do entendimento de que, se as mídias sociais modificam a forma de interação entre os sujeitos do processo de comunicação, tornando-o mais interativo e participativo, consequentemente elas estimulam a prática da comunicação pública, contribuindo desse modo para o exercício da cidadania.

Com as informações obtidas pela coleta dos dados pudemos perceber que muito ainda tem que se percorrer. Conforme os dados coletados, vimos que os questionamentos feitos para o governador são respondidos de forma dinâmica, sem seleção de assuntos, com o intuito maior de buscar um diálogo com o seguidor. E os assuntos tratados nesta mídia, como aponta a assessora, dizem respeito a interesses coletivos. Porém, foi notado, quando analisamos as respostas obtidas pelo questionário aplicado com seus seguidores, que muitos questionamentos ficaram sem respostas ou foram dotados de respostas insatisfatórias.

Através dos sites TweetRank e TweetStast, percebemos que o governador possui um nível de interação muito baixo com seus seguidores. Essa interação está relacionada, segundo critérios dos sites, com a capacidade de responder aos seguidores. Percebe-se que, mesmo o governador e sua equipe afirmando que seu perfil no twitter tem como principal objetivo dialogar com os seus seguidores, isso não ocorre com tanta frequência. Mas também não podemos deixar de apontar que poucos seguidores enviaram um questionamento para o governador. Esse fato foi marcado por $70 \%$ dos que responderam essa questão.

A partir dos dados da pesquisa, vê-se que o cidadão ainda não utiliza o twitter como um canal de comunicação para atingir e se aproximar do governante. O que podemos entender com esses dados e todos os outros já analisados neste estudo é que o twitter é uma mídia que proporciona maior interação entre as pessoas; inclusive, essa é a maior característica apontada tanto pelos seguidores, quanto pelo governador, para se ter um perfil. Contudo, ainda pouco se utiliza essa característica para buscar uma aproximação maior entre cidadão e governante e, assim, estabelecer um canal de diálogos e assuntos de relevância pública.

Pierre Zémor (1995) afirma que a função precípua da comunicação pública é transmitir informações do governo. O twitter mantido pelo governador Marconi Perillo, nesse sentido, procura realizar essa função, a partir de uma equipe profissional atuante. Porém, deve-se ir além desse processo de transmitir informações.

Em uma sociedade democrática, são essenciais o diálogo e o exercício da cidadania. Nessa perspectiva, deve-se pensar que as mídias sociais podem possibilitar uma maior participação nos debates públicos e, com isso, certamente, a prática da comunicação pública e da cidadania serão estimuladas, possibilitando, assim, uma relação mais estreita entre governo e sociedade.

Dentro desse contexto, as mídias sociais, especificamente o twitter, podem ser um locus para as discussões de interesse público. Para tanto, torna-se necessário que os governantes 

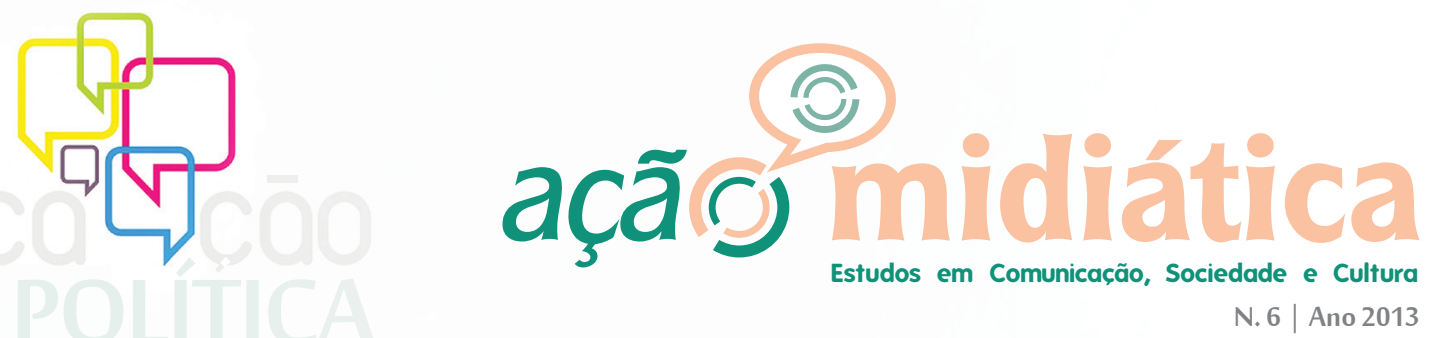

Universidade Federal do Paraná | Programa de Pós-Graduação em Comunicação

utilizem essa mídia para esse fim, e não apenas para a divulgação política de sua imagem e busca de votos.

$\mathrm{O}$ cidadão, enquanto partícipe e usuário dessas mídias, também deve cobrar essa postura de seus governantes, para que eles possam utilizá-las como um verdadeiro espaço de interlocução e de debates de assuntos de real interesse público.

Como constatamos com essa pesquisa, muito deve ser percorrido tanto por parte do governante - no sentido de transcender o uso dessa mídia como busca de construção de imagem pública positiva e como instrumento de divulgação de informações - quanto também por parte do usuário dessa mídia, no que tange a reconhecer esse espaço como instrumento de comunicação que possibilita um diálogo e aproximação com o governante.

Assim, entendemos, com esse estudo, que as mídias sociais proporcionam um espaço para a prática da comunicação pública e para o exercício da cidadania. Todavia, conforme nos apontaram os dados obtidos, essa comunicação ainda não é realizada; tanto por parte do governador, pois seu perfil tem como característica principal a transmissão de informações, contrariando o que o mesmo afirma nas suas respostas, quanto também por parte do seguidor, que ainda não utiliza esse espaço para essa finalidade.

Cabe salientar, entretanto, que a utilização e a apropriação das mídias sociais, tanto pelos governantes quanto pelos cidadãos, são, de fato, um fenômeno recente. Dessa forma, entende-se que deverá ocorrer um processo de amadurecimento diante dessas mídias, criandose, assim, uma possibilidade para a prática da comunicação pública.

Assim, concluímos que o twitter do governador Marconi Perillo é um espaço para uma comunicação mais próxima com o cidadão, porém ainda não possibilita uma comunicação essencialmente dialógica e com espaço para debater assuntos de relevância pública, como aponta característica da comunicação pública, ressaltada por diferentes autores. De fato, percebemos que o twitter, enquanto mídia social, tem a possibilidade de proporcionar uma comunicação verdadeiramente pública, pois é um novo canal de comunicação entre governante e cidadão - e vice versa.

Nesse sentido, vemos que o twitter do governador Marconi Perillo é um locus voltado à transmissão de informações do governo. Portanto, está mais afastado do ideal de ser uma ferramenta para estabelecer uma interação realmente pública com o seguidor. O fato é que ainda temos muito que amadurecer, tanto por parte do governo, no sentido de realmente fazer dessa mídia um espaço para diálogos e discussões, quanto por parte também do seguidor, que pode vir a usar essa mídia para dialogar de forma profícua com o poder público. 
